Jol. 11, No. 38, January, 2016, 239-254

\title{
COMPARISON BETWEEN DIFFERENT CODES IN CALCULATION OF THE EFFECT OF FATIGUE ON STEEL STRUCTURES
}

\author{
N. Mahmoud, F. Salem and M. Mamdouh \\ Structural Eng. Dept., Mansoura University, Mansoura, Egypt
}

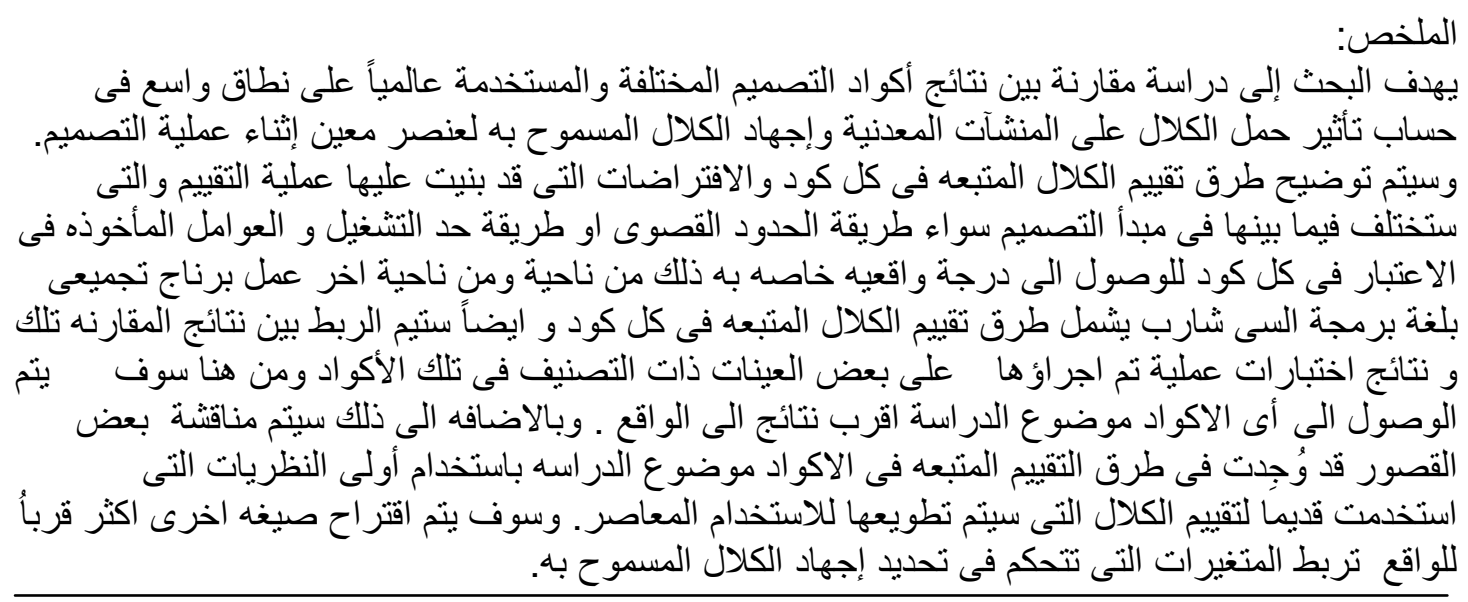

\section{ABSTRACT}

This paper presents a study for comparison between different codes which widely used globally in the calculation the allowable fatigue strength for a particular element during the design process. The fatigue assessment method, the assumptions, the considerations followed in each code will be clarified and the difference between them either in the design principle, whether load and resistance factor method or the allowable stress design method or the factors that was taken into consideration to achieve their vision of the reality. On the other hand, an overall program is performed with C\# programming language to facilitate the fatigue assessment process in each code. Also, another comparison also link those results with test result was conducted on many samples which categorized in those codes then we will reach which of code under consideration near to the founded in deed and there would be many trials to avail these test result to perform more realistic S-N curves using the high ordered polynomial equation. In addition, Some shortcomings would be indicated belong to the fatigue assessment method in the considered code using a traditional neglected theory helped formerly in the fatigue assessment and it would be adapted to the contemporary uses. Higher order proposal formula approach to the results founded in deed contained the governing variables in determining the allowable fatigue strength.

\section{KEYWORDS: Fatigue in steel, Fatigue Assessment Methods, Repeated loading}

\section{1- INTRODUCTION:}

Fatigue in metals is the process of initiation and growth of cracks resulting from of repetitive cyclic loading. If crack became a non-normal beyond the permitted limits 
for metal, failure of the member can result when the un-cracked cross-section is reduced enough such that the member is no longer able to overcome the effects of the internal forces for the crack grows in an unstable mode. The fatigue phenomenon can take place at produced repeated stress levels (calculated on the initial cross-section) that are basically less than those concerned with failure under static loading conditions. The usual condition that produces fatigue cracking is the exposing to a large number of stress cycles. Therefore, the studying of the fatigue phenomenon is a very essential for every constructed thing at which fatigue is expected to be taken place especially, the types of civil engineering applications that are liable to fatigue cracking include structures such as bridges, crane structures, stacks and masts, and offshore structures.

\section{2- HISTORICAL PERSPECTIVE ON FATIGUE PROCESS}

Going back to 1842 with the incident of Versailles, it is the first time to observe that a material, when subjected to repeated (or dynamic) loading, would fail at a much lower stress than that required to cause failure in static loading. The failure under dynamic loading was called "fatigue". Later, it was found that fatigue is the cause of nearly $90 \%$ of mechanical failures. So, the study on fatigue became very significant and since then several works have been carried out in order to study different features of fatigue failure and to develop various methods to prevent these severities resulting from this mechanical phenomenon.

\section{3- FATIGUE RESISTANCE CURVES}

Many studies on this phenomenon have been carried out in the nineteenth century to put limitations helping in keeping any considered application under the safe gamp against the fatigue threats. Beginning by August Wholer [1] who worked on fatigue remarks shown in the drawing of a fatigue failure in an axle, sketched by Joseph Glynn [2] following The Versailles accident, 1842. Wholer produced the first systematic of S-N Curves by investigating the failure mechanism of locomotive axles by applying controlled load cycles. He introduced the concept of rotating-bending fatigue test. Using numerous testing procedures to generate the required data for a proper S-N diagram by plotting the scattered nominal stress amplitude S versus cycles to failure $\mathrm{N}$ by a log-log scale then; he approximated those scattered points by a linear relation representing the mean of the data. From these several tests, he characterized the fatigue behavior of materials depending on those resulting curves and used them to minimize the problem of fatigue by lowering the stress below the critical line which represented the fatigue resistance for a particular component. He also put a first use of the term of the stress range in assessing fatigue. Wholer approach is the basis of the fatigue assessment method followed in all established principles in global codes and practice as it is considered as only an implementation of his theory with slightly changes.

Gerber and Goodman [3] investigated the effect of mean stress on fatigue parameters and developed proposal theories for fatigue life. Depending on these theories, the competent designers started to perform fatigue analysis in construction development and were able to predict the fatigue life better than ever before. In the beginning of the Twentieth century, the role of Basquin [4] came as a supplementing for Wholer work. He used the nature of the Wholer curves and proposed his mathematical log-log representation indicating the relation between the stress versus the number of stress cycles which may be expressed as follows:

$$
\mathrm{S}=\mathrm{K} \mathrm{N}^{-\mathrm{m}}
$$

Where:

$\mathrm{S}=$ the fracture stress in a particular specimen.

$\mathrm{N}=$ the number of stress cycles at the fracture stage for a particular specimen.

$\mathrm{K}$ and $\mathrm{m}=$ constants depending on the resulting curve with respect to the type of material and the type of test. 
After the evolution of the relationship between the two variables of the above Basquin relation, some complemented theories began to arise to develop a comprehensive concept for the fatigue phenomenon since the initiation of cracks up to the stage of collapse. Matsuishi et al. [5] supposed the two cycle counting methods which can be applied for any recorded stress history for a particular element under the assessment process. Palmegren and Miner [6,7] co-operated intellectually to introduce the linear cumulative fatigue damage criterion as recognized now as the Palmgren-Miner linear damage rule which states the condition of the failure occurrence and can be written by the following form:

$$
\sum \bar{N} \leq 1.00
$$

The above representation has been abundantly used in fatigue design and, despite its many shortcomings, remains a convenient tool in fatigue life predictions. Smith [8] developed his own style to assess any element exposed to any repeated loading against fatigue with referencing to the main objective of Wholer curve was only for the determination of the fatigue endurance limit below which the material can suffer an infinite number of stress cycle without occurrence any failure. Using this endurance limit with the aid of the static properties, he plotted the safety boundary inside which there is no fatigue failure would occur.

\section{4- THE PRINCIPLE OF ASSESSING FATIGUE IN THE MOST USED REGULATIONS}

Most of codes of practice developed their own principle by performing the fatigue test on number of specimens representing the proposal details found in the constructions exposed to fatigue loads. For each test a scattered curve is plotted and with the linear regression analysis, an approximated relation would be developed. With a thoughtfulness of the safety consideration, confidence intervals of $95 \%$ would be achieved then; the lower bound from these intervals would be the representation of all fatigue resistance curves with many different forms, which will be mentioned as follows:

In AASHTO_[9] is considered as the most regulations commonly used in America society for steel construction, which specializes in the development of a full concept for the design of Highway bridges. A large number of tests were conducted by the National Cooperative Highway Research Program (NCHRP) on various eight details types. After having the difficult evaluated scattered data curves, a statistical method (primarily linear regression analysis) [10]. This can be the reason to the fact that the relationship between the fracture stress range and the number of cycles is a $\log -\log$ in nature. . Without differentiating between the nature of the fatigue resistance curves for fatigue either due to flexural or due to shear, uniform and parallel eight fatigue resistance curves as shown in fig (1) were developed with a constant slope of -3 up to the constant value of the fatigue resistance at the threshold stress range below which the element would endure an infinite number of stress cycles without occurring any fatigue failure., each curve can be represented mathematically with respect to the factors which service the load and resistance factor as a method of design and the minimum fatigue strength could be endured as the following:

$$
\text { ((f) })_{\downarrow} n=\text { MAXof }\left[(A / N)^{\uparrow}(1 / 3), \quad 0.5 F_{\downarrow} t h\right]
$$

Where:

$\left((\mathbf{f})_{\downarrow} n=\right.$ The required allowable fatigue strength for a specific category.

$\mathrm{A}, \mathrm{F}_{\mathrm{th}}=\mathrm{a}$ constant depending on the selected detail category.

$\mathrm{N}=$ number of stress cycles for the element under consideration, can be determined by the cycle counting method proposed by Matsuishi et al. or by depending on the life time of the bridge ( $\mathrm{N}=365 \times \mathrm{Y} \times A D T T s \mid \times n)$

Where: 
$\mathrm{Y}=$ the life time of the bridge.

$\mathrm{ADTT}_{\mathrm{sl}}=$ the average daily truck traffic.

$\mathrm{n}=$ the number of cycles are occurred by each truck.

It is noticed that the life time of a considered bridge can be assumed 75 years as an average so, the expected value of the number of cycle per each truck would be considered as follows with respect to the corresponding detail categories:

Table (1)

\begin{tabular}{|c|c|c|}
\hline Category & ADTT $_{\text {sl }}$ & Recommended value of $\mathbf{n}$ \\
\hline A & 530 & 0.9972 \\
\hline B & 860 & 0.9956 \\
\hline B $^{\prime}$ & 1035 & $\mathbf{0 . 9 9 6 8}$ \\
\hline C & 1290 & $\mathbf{0 . 9 9 6 8}$ \\
\hline C & $\mathbf{7 4 5}$ & $\mathbf{0 . 9 9 8 9}$ \\
\hline D & 1875 & $\mathbf{0 . 9 9 9 7}$ \\
\hline E & 3530 & 0.9994 \\
\hline E & 6385 & 0.99999 \\
\hline
\end{tabular}

But the values of $n$ always are bigger than the unity, so, we can say that at $Y \geq 75$ years, the expected value of the fatigue strength must be $0.5 \mathrm{~F}_{\text {th }}$.

Concerning the Railroad constructions, another specialized regulation called AREMA [11] limited the number of stress cycles constant at 2,000,000 cycles in the case of single track and over 2,000,000 cycles for double track or more and followed the simplest principle in the assessment process and limited the fatigue strength by the endurance fatigue limit and would be determined by:

Table (2)

\begin{tabular}{|c|c|c|}
\hline \multirow{2}{*}{ Stress Category } & \multicolumn{2}{|c|}{ Allowable fatigue strength } \\
\cline { 2 - 3 } & $2,000,000$ & Over 2,000,000 \\
\hline A & 24 & 24 \\
\hline B & 15 & 16 \\
\hline B & 14.5 & 12 \\
\hline C & 13 & 10 \\
\hline D & 10 & 7 \\
\hline E & 8 & 4.5 \\
\hline E & 5.8 & 2.6 \\
\hline F & 9 & 8 \\
\hline
\end{tabular}

Another provisioned code govern the steel construction in the south part of the North America continent with respect to another factors taken into consideration the Canadian regulations [12] followed the same principle at which a relation governing the fatigue resistance for nine detail categories as shown in fig(2). This relation is connecting between the required fatigue strength of each specified detail category and the corresponding estimated number of stress cycles as the same attitude of the loglog relation as follows:

$\mathbf{F}_{s r}=$ MAXof $\left[\left(\frac{Y}{N n}\right)^{\frac{1}{3}}, 0.5 F_{s r t}\right]$

Where:

$\mathrm{Y}, \mathrm{F}_{\mathrm{srt}}=$ is a constant is depending on the selected stress category.

$\mathrm{N}=$ number of passage of the moving load. 
$\mathrm{n}=$ number of stress cycles per each passage of the moving vehicle.

On the other side of most followed approaches, we will find different considerations in Eurocode 3 [13] which carried their own tests on various details types , draw the results as scattered curves differing from the fatigue due to repeated flexural stress and the fatigue due to repeated shear stress. So, it approximated the scattered curves either to fourteen flexural fatigue resistance curves or to two shear fatigue resistance curves as shown in fig (3). All flexural fatigue resistance curves have two variable slopes of -3 and -5 , those curves are featuring by three hot-spotted allowable fatigue stress range $\left(\sigma_{\mathrm{c}}\right.$ is the reference value at $\mathrm{Nc}=2,000,000$ cycles, $\sigma_{\mathrm{D}}$ is the constant amplitude fatigue loading at $\mathrm{N}_{\mathrm{D}}=5,000,000$ cycles, $\sigma_{\mathrm{L}}$ is the cut-off limit at $\mathrm{N}_{\mathrm{L}}=100,000,000$ cycles) but the shear fatigue resistance are featuring by a unique slope of -3 up to the cut-off value at $\mathrm{N}_{\mathrm{L}}=100,000,000$ cycles. In the assessment process, regulations in Eurocode 3 trod another attitude by making the fatigue resistance to be constant at the reference value at $\mathrm{N}=2,000,000$, then transferring the computed stress range from its nature of constant amplitude loading to the reality of the variable amplitude loading by multiplying it by modification factors called the damage equivalent factors with respect to the limit state as a method of design. This would be taken place as follows:

Actual stress range $\mathrm{x}$ F.O.S $\leq \frac{\text { Fatigue strength }}{\text { F.o.s }}$

Where:

$$
\min \text { of }\left(\lambda_{1} \times \lambda_{2} \times \lambda_{3} \times \lambda_{4}, \lambda_{\max }\right) \times \varphi \times \Delta \sigma \leq \frac{\Delta \sigma_{\mathrm{C}}}{\gamma_{\mathrm{Mf}}}
$$

$\lambda_{1}=$ is depending on either the critical length of the element and the position of section under consideration in the roadway bridges or the critical length and the type of train load model in the railway bridges (is the factor that governs the determination of the damage factor).

$\lambda_{\mathbf{2}}=$ is depending on the volume of traffic per year (is recommended to be 1.00 for $\mathrm{Q}_{\mathrm{mi}}=480 \mathrm{KN}$ with medium flow rate of heavy vehicle)

$\lambda_{3}=$ is depending on the design life of bridges (is recommended to be 1.00 for life time $=100$ years)

$\bar{\lambda}_{4}=$ is depending on the effect of existing of more than one lane or track (is approximately recommended to be 1.00 when considering that there is only one slow lane in the bridge).

$\lambda_{\max }=$ is the maximum allowable damage factor with respect to the constant amplitude fatigue limit.

$\Phi=$ is the impact factor.

$\Delta$ a $=$ is the calculated based on the considered fatigue load model either the fatigue load model 3 for roadway bridge or fatigue model 71 for the railway bridges.

$\Delta \sigma_{\mathrm{C}}=$ the detail category under consideration.

$\gamma_{\mathrm{M} \text { }}=$ the factor of safety for the fatigue resistance.

So, some extrapolations can be mentioned as below:

- Min of $\left(\lambda_{1}\right.$ or $\left.\lambda_{\max }\right)$ which is depending on the critical length with respect to the position of the considered section.

(1) For sections at the mid span:

The value of $\lambda_{\max }$ would govern up to the critical length $<66 \mathrm{~m}$ as illustrated in fig (5)

(2) For sections at supports

The value of $\lambda_{\max }$ would govern up to the critical length $<25 \mathrm{~m}$ as illustrated in fig (5).

In Egypt, previously, the fatigue assessment procedure [14] using the Allowable Stress Design method. These regulations simulated the work of old editions of American society for steel constructions by the same resulting log-log relation between the required fatigue resistance and its expected number of stress cycles as the following formula:

$$
\log \mathrm{F}_{\mathrm{sr}}=\log \mathrm{a}-\mathrm{m} \log \mathrm{N}
$$

Where:

$\mathrm{a}=$ is a constant depending on the selected category.

$\mathrm{m}=$ is the slope of the fatigue resistance curve for a specified stress category.

$\mathrm{N}=$ is the number of stress cycles. 
Nowadays, the Egyptian Permanent Committee for the Code of Practice for Steel Construction and Bridges has finished their work on the proposal fatigue assessment procedure followed the load and resistance factor as a design method [15]. Fourteen categories have been listed simulating the listed categories in Eurocode 3 and followed their own principle by make the fatigue strength constant at the reference value at $\mathrm{N}_{\mathrm{c}}=2,000,000$ cycles and convert the actual stress range from the case of the constant amplitude loading into the case of the variable amplitude loading using the maximum allowable value of the damage as the following:

$$
\lambda_{\max \times \varphi \boxminus \Delta \sigma} \leq \frac{\Delta \sigma_{\mathrm{C}}}{\gamma_{\mathrm{Mf}}}
$$

Where:

$\lambda_{\max }=$ is the maximum allowable damage factor depending on the position of the section under consideration and the critical length for the studied element.

$\Phi=$ is the impact factor.

$\Delta$ [ $=$ is the calculated based on the considered fatigue load model either the fatigue load model 3 for roadway bridge or fatigue model 71 for the railway bridges.

$\Delta \sigma_{\text {घ }}=$ the detail category under consideration.

$\gamma_{\mathrm{M} \text { च }}=$ the factor of safety for the fatigue resistance.

In order to realize of all considerations and assumptions in the studied regulations and to facilitate the process of evaluation fatigue in each code, a program has been carried out by the $\mathrm{C \#}$ programming language to gather all the assumptions concerning fatigue assessment method followed in all considered codes and practice in a unified platform as shown in fig $(6,7,8,9,10,11)$.

\section{5- A PERFORMED PROGRAM TO SUMMARIZE ALL THE ABOVE CONSIDERATIONS}

A program was performed by the $\mathrm{C} \#$ programming language to facilitate the fatigue assessment mentioned in each considered code as shown in fig $(6,7,8,9,10$ and 11) which representing code of practice of (AASHTO, AREMA, Canadian, European, ECS using ASD method and ECS using LRFD method respectively).

\section{6- COMPARISON WITH THE TEST RESULTS}

Fig $(12,13,14,15)$ shows the fitted scattered actual test results conducted by (NCHRP) in some particular detail categories with their corresponding results calculated by the considered codes of practice to prove which regulations give the nearest results to the reality with hints clarified the convergence ratio.

From the previous indicated considerations we would notice that:

All the considered codes of practice are depending on the principle of Wholer in developing the S-N curves by using the linear regression technique of conducted tests for numerous considered detail types. But it is known that the curve regression technique has more accuracy than the linear one, so that, many trials have been carried out using the least error square for the concluded scattered data to develop higher degree functions.

\section{7- MORE ACCURATE HIGHER DEGREE CURVES FOR SOME DETAIL CATEGORIES}

According to the test results introduced in (NCHRP), numerous specimens including (Rolled Sections, Welded beams, Cover plated beams, Beams with web attachments named by A, B, E, E` detail categories) were tested, so we can use these scattered results to develop a more accurate new formula from the third degree as the possible highest degree apart away from the Complexity (Satisfying the lower bound of confidence interval of $95 \%$ ). The new formula would be as the following:

$$
\log \mathrm{F}_{\mathrm{sr}}=\mathrm{a}+\mathrm{b}(\log \mathrm{N})+\mathrm{c}(\log \mathbf{N})^{2}+\mathrm{d}^{(\log N)^{3}}
$$

Table (3)

\begin{tabular}{|c|c|c|c|c|}
\hline $\mathrm{d}$ & $\mathrm{c}$ & $\mathrm{b}$ & $\mathrm{a}$ & Detail Under Testing \\
\hline 0.0025 & 0.007 & -0.498 & 3.799 & $\mathrm{~A}$, (Rolled Section) \\
\hline 0.1731 & 3.152 & 18.78 & 35.166 & $\mathrm{~B}$, (Welded Beam) \\
\hline 0.296 & -5.22 & 30.3 & -56.54 & E, (Cover Plated Beams) \\
\hline 0.0927 & -1.844 & 11.77 & -23.18 & E`, (Beams with Web Attachments) \\
\hline
\end{tabular}


Where:

$\mathrm{a}, \mathrm{b}, \mathrm{c}, \mathrm{d}=$ Constants are produced from performing the higher ordered linear regression using each test results for a particular detail category.

$\mathrm{F}_{\mathrm{sr}}=$ the required fatigue strength at a particular number of stress cycles $(\mathrm{N})$.

We will re-compare between the results of the tests and the results of the considered codes of practice with considering the results are produced by the new formula, the decision of the nearer results will turn to these results calculated by the new produced formulas as indicated in fig $(16,17,18,19)$.

Back to the traditional method developed by Smith in order to assess fatigue for a particular element knowing its static properties represented in the ultimate strength, yield strength and the distinctive property for material against fatigue loading known as the endurance limit. He used all of these properties to give a safely boundary inside which any represented sample by its actual maximum and minimum stresses due to its fatigue loading, would endure fatigue loading safely. Depending on what provided in this theory and how to use it in the fatigue assessment process, there would be many shortcomings are found in the regulations mentioned in all considered codes and practice and can be listed as follows:

- $\quad$ The change in grade of steel affected in the fatigue assessment process.

- $\quad$ The term of stress range cannot be the overall used concept in the fatigue assessment process.

- The only purpose for S-N diagram is not originally to be approximate to introduce the fatigue strength curve but only to determine the endurance limit for considered specimens.

To overcome these drawbacks, a proposal method would be introduced using the Smith theory to make it adaptable nowadays using the minimum stress range as the endurance limit for a considered stress category with respect to the change of grade of steel as shown in fig $(20,21$ and 22).

\section{CONCLUSION}

(1) The assumptions concerning fatigue assessment in Eurocode 3 characterized in its more details starting with the segregation between the fatigue assessment due to the flexural stress range or the shear stress range.

(2) All of codes assumed that the effect of constant amplitude loading during the design process is similar to what happen in the reality which seems with unpredicted amplitude loading except the Eurocode 3 which developed the damage factors especially to simulate the reality.

(3) Comparing between the results from codes and practice with the test result we would find out that North America specification would be the nearest.

(4) The higher ordered linear regression would be better than the representation of the straight line so, it is supposed to represent the scattered S-N curve produced in the test data by a cubic equation to fit the scattered well.

(5) Depending on the Smith theory, both of grade of steel and the actual mean stress has an effect cannot be neglected in addition, the concept of stress range must not be a comprehensive in the fatigue assessment process.

\section{REFERENCES}

[1] Wöhler, A., Über die Festigkeitsversuche mit Eisen and Stahl, Zeitschrift für Bauwesen Volume 20, (1870).

[2] Schutz, W., "A history of fatigue". Engineering Fracture Mechanics, pp. 54: 263-300, (1996).

[3] Smith RA, Hillmansen S., "A brief historical overview of the fatigue of railway axles", Proc. Inst. Mech. Eng., pp.218:277, (2004).

[4] Basquin, O, H., "The expontial law of endurance tests", ASTM, Vol. 10, page 625, (1910).

[5] Matsuishi, M. \& Endo, T., "Fatigue of metals subjected to varying stress", Japan Soc. Mech. Engineering, (1968). 
[6] A. z. Palmgren - " Die lebensdauer von kugellagern",z.Ver.Deutsch.ing.68,339 (1924)

[7] M, A. Miner., "Cumulative Damage in Fatigue", J. Appl. Mech. 12, A1S9 (1945).

[8] Shigley, J.E. and Mitchell, L.D., Mechanical Engineering Design, Fourth Edition, McGraw-Hill, New York, p. 273, (1983).

[9] American Association of State Highway and Transportation Officials, "AASHTO

LRFD Bridge Design Specifications," Sixth Edition, Washington, D.C., (2012).

[10]Fisher, J.W and Keating P. B., "Fatigue Behavior of Full-Scale Welded Bridge Attachments", NCHRP Report 488.1(86), National Cooperative Highway Research Program, (1986).

[11] Harry B. and Cundiff, P.E., "Design Criteria for Bridges", Section 11-part 2, Atlanta, Georgia.

[12] Canadian institute of steel constructions, "CISC LRFD Bridge Design Specifications", Seventh Edition, (2000).

[13] EN 1993-1-9: Eurocode 3: Design of steel structures, Part 1.9: Fatigue, (2003)

[14] Egyptian Code of Practice for Steel Construction and Bridge, "Allowable Stress Design Method", First Edition, (2001).

[15] Draft of Egyptian Code of Practice for Steel Construction and Bridge, "Load and Resistance Factor", First Edition.

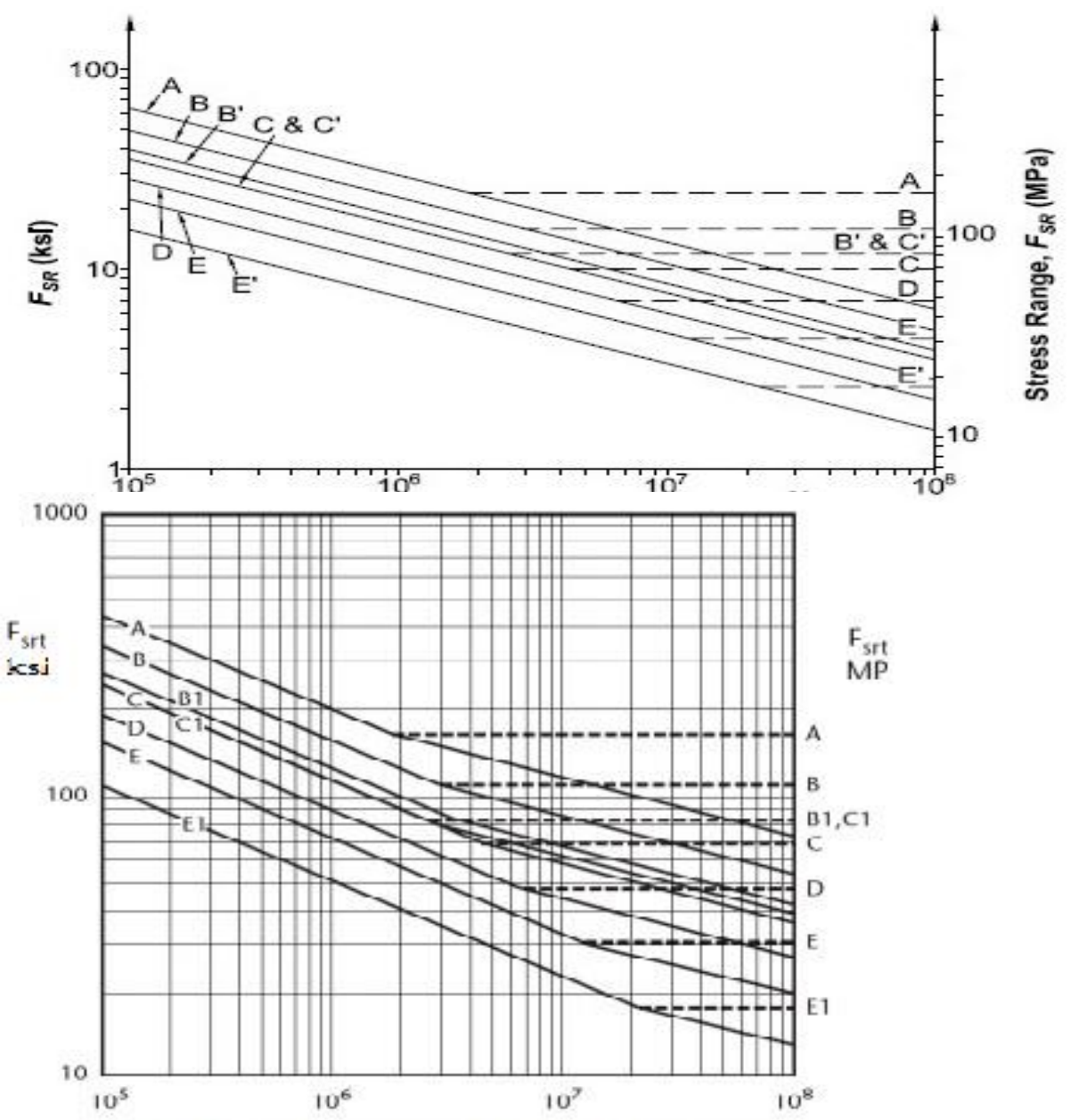

Fig (2): S-N Curves supposed by the Canadian Provisions 

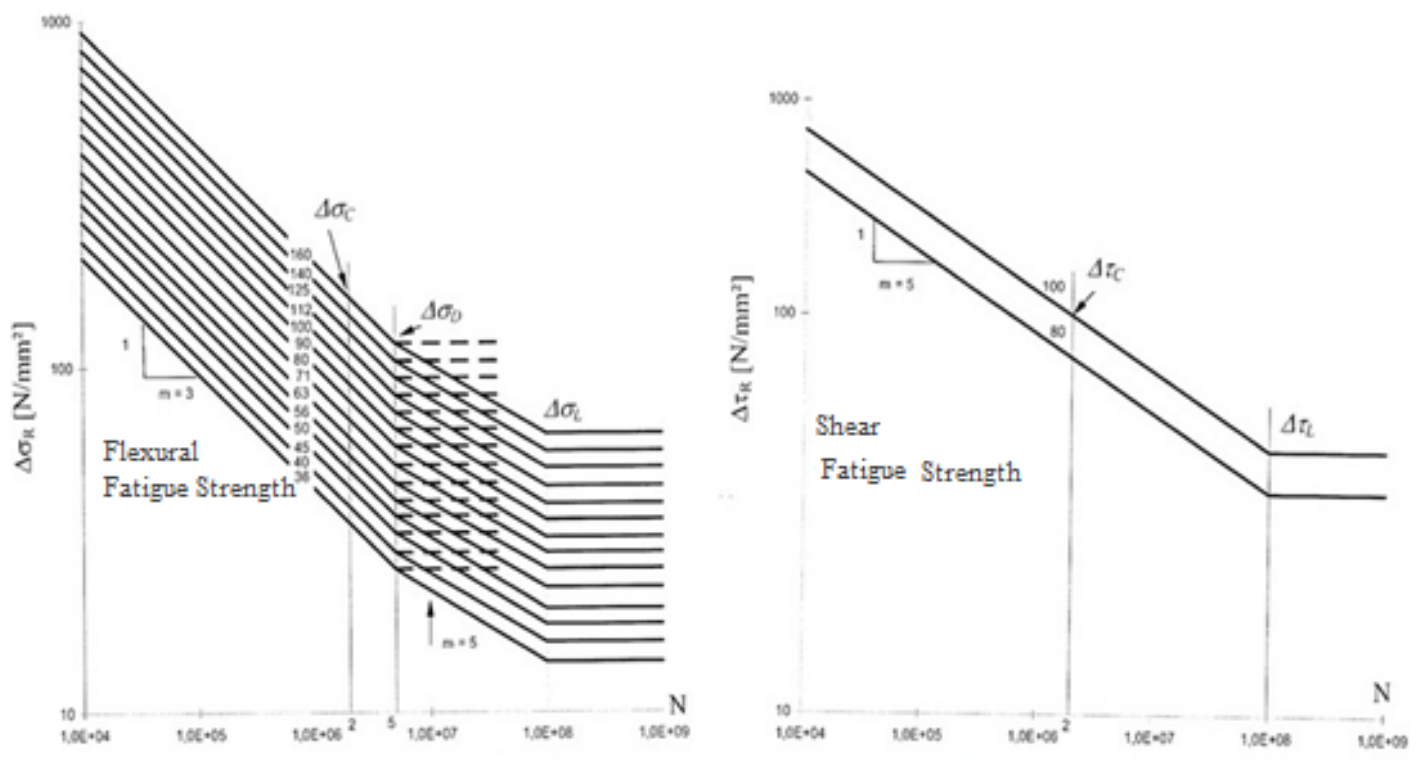

Fig (3): S-N Curves followed in Eurocode 3 and the LRFD Egyptian code of practice

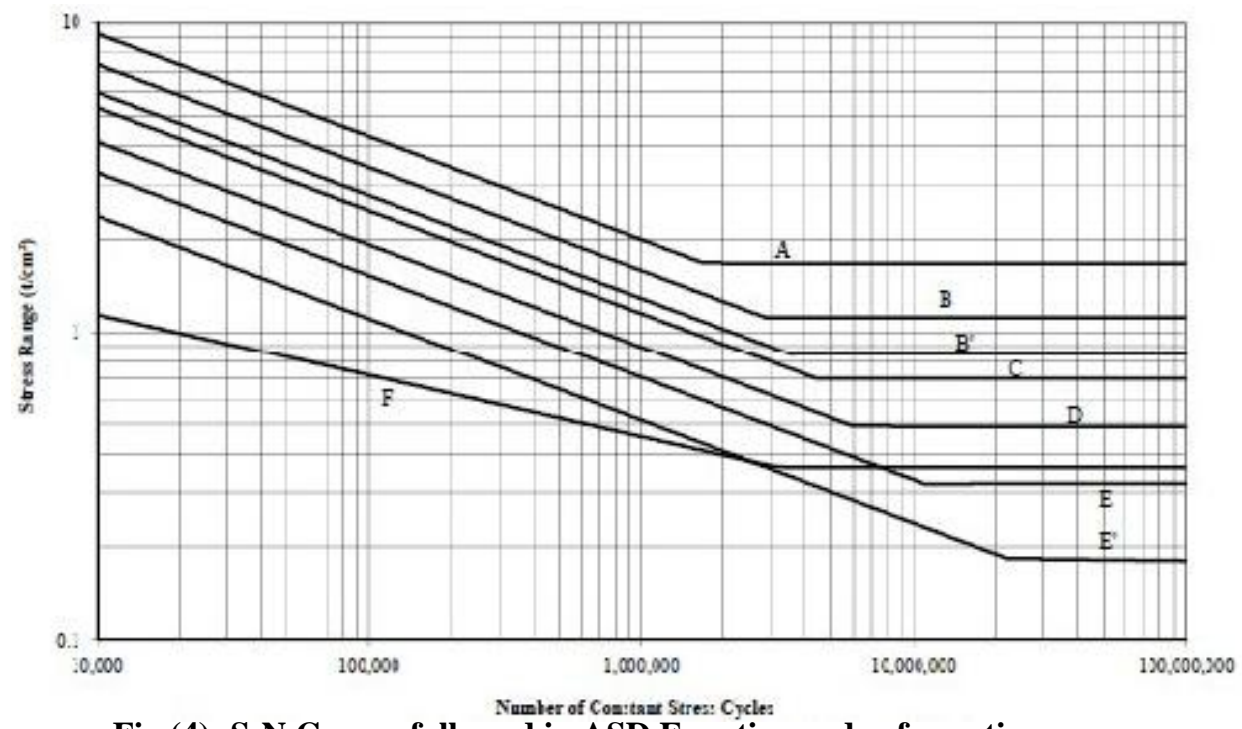

Fig (4): S-N Curves followed in ASD Egyptian code of practice.

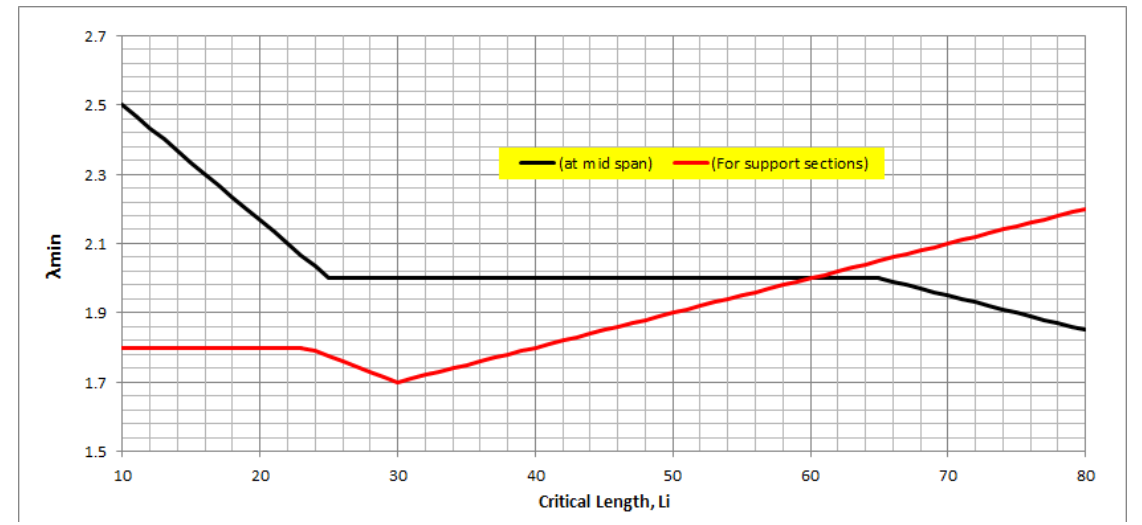

Fig (5): The recommended values of the minimum damage factor considering the case of $(\lambda 2=1.00, \lambda 3=1.00$ and $\lambda 4 \approx 1.00)$ 


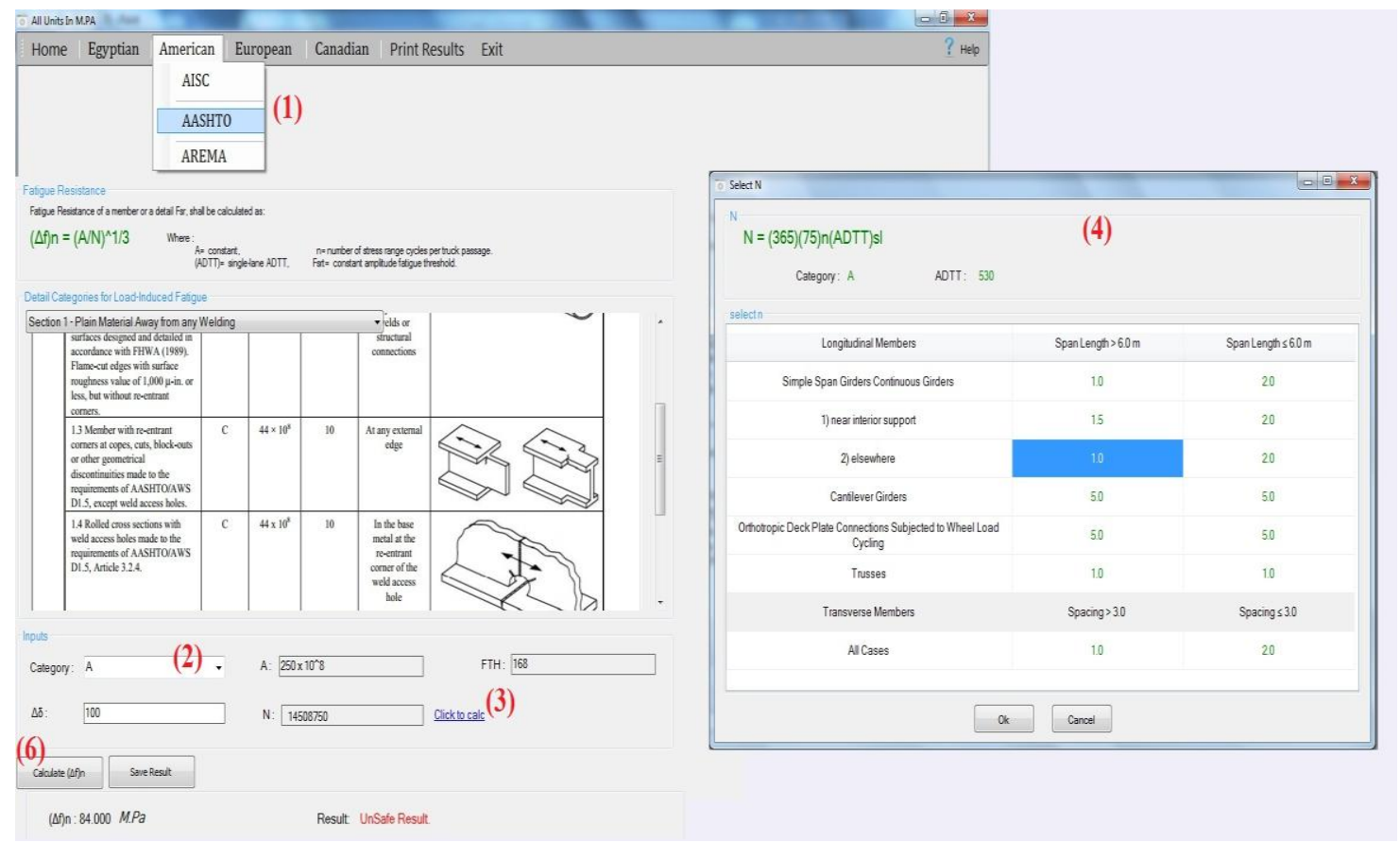

Fig (6): A branch of the performed program representing the AASHTO specification.

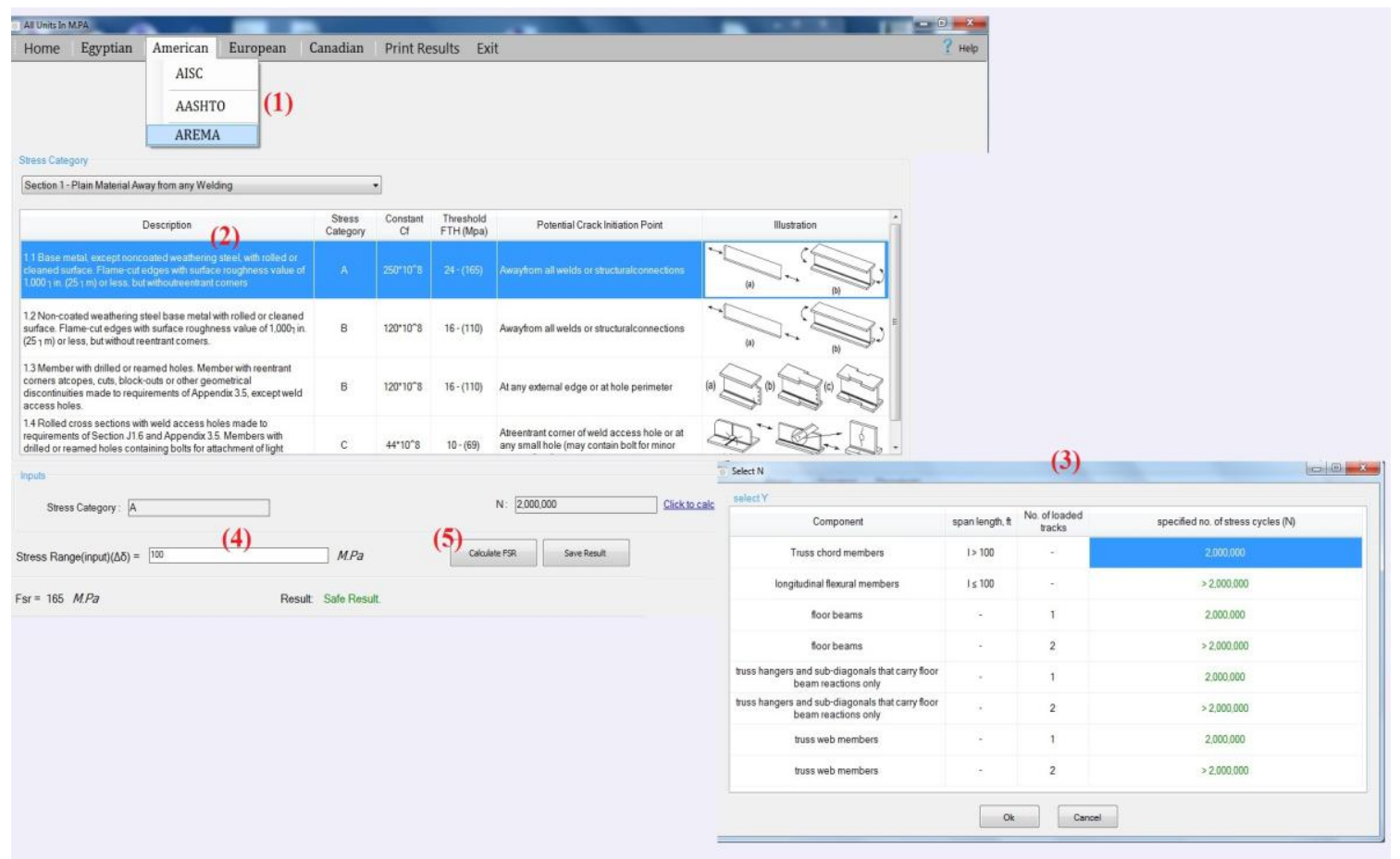

Fig (7): A branch of the performed program representing the AREMA specification. 


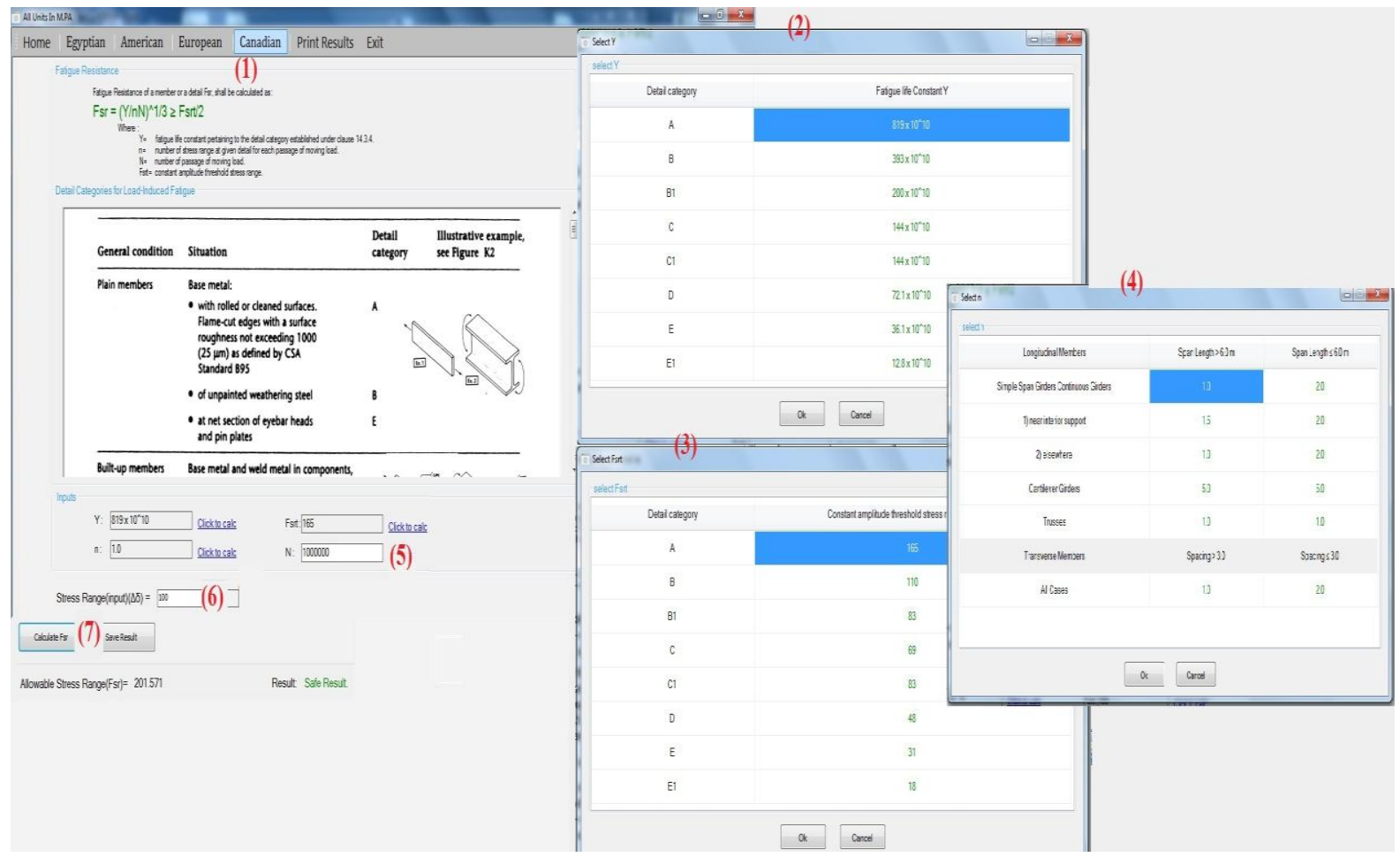

Fig (8): A branch of the performed program representing the Canadian specification.

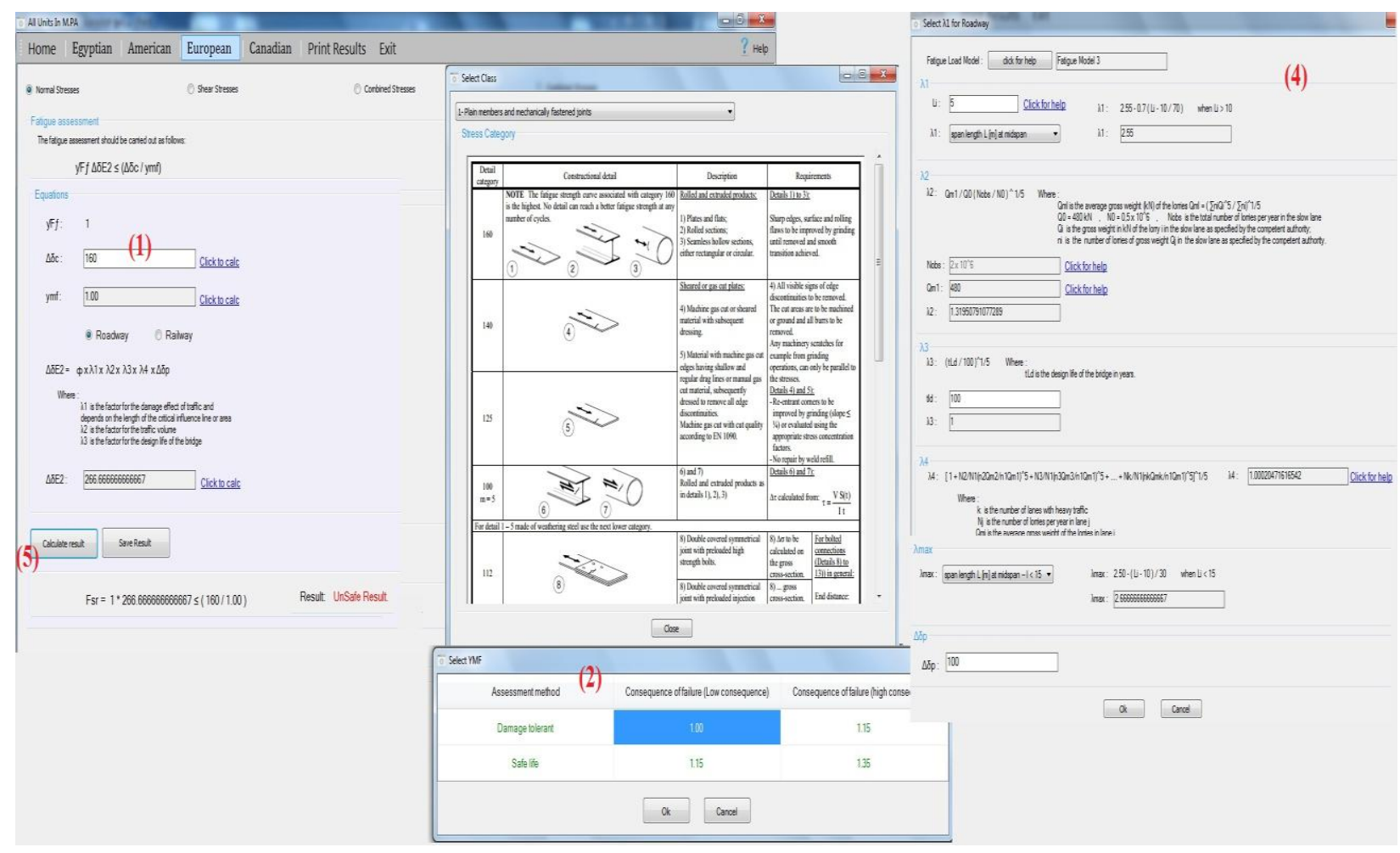

Fig (9): A branch of the performed program representing the Eurocode 3 specification. 


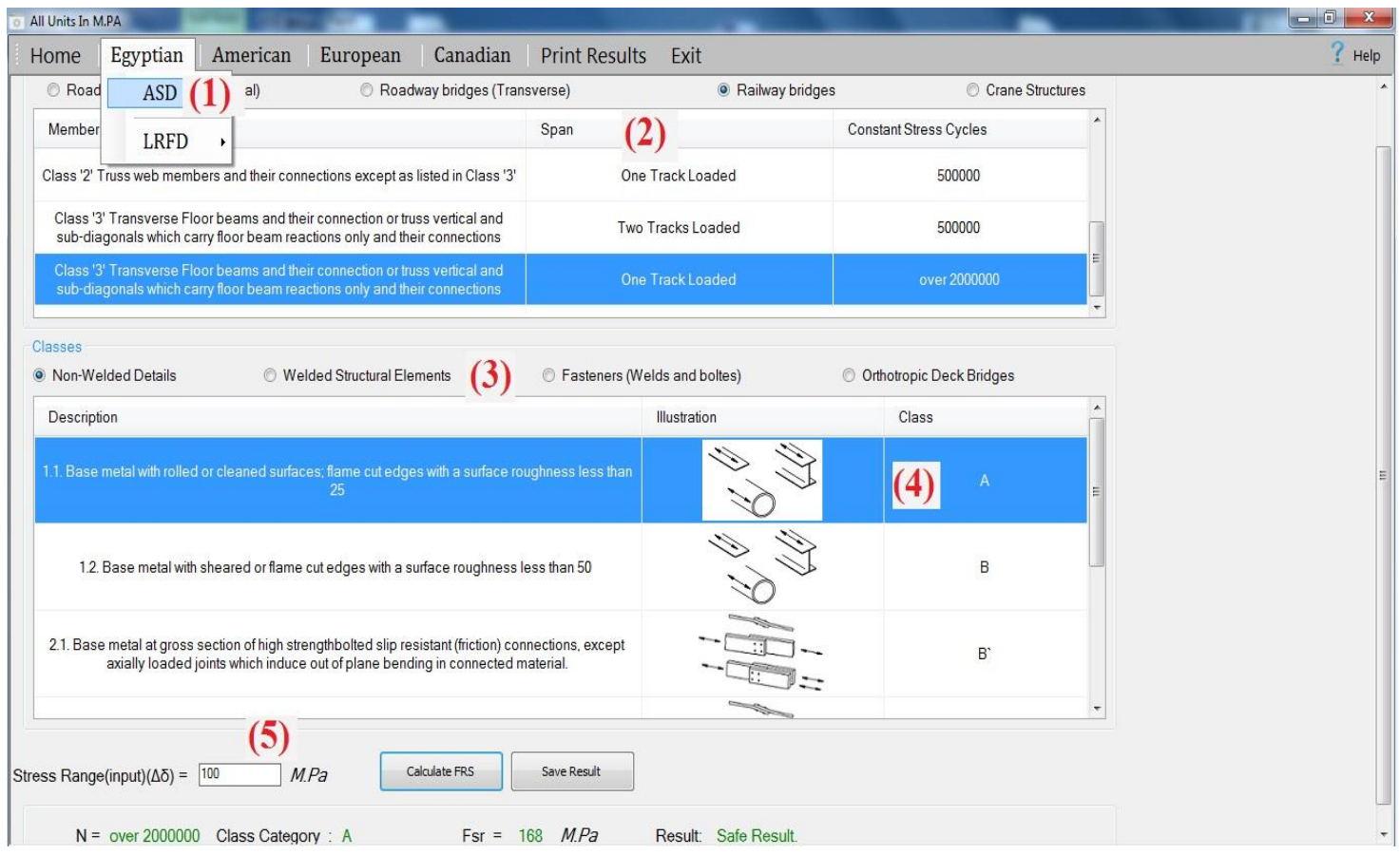

Fig (10): A branch of the performed program representing the ASD Egyptian code of practice.

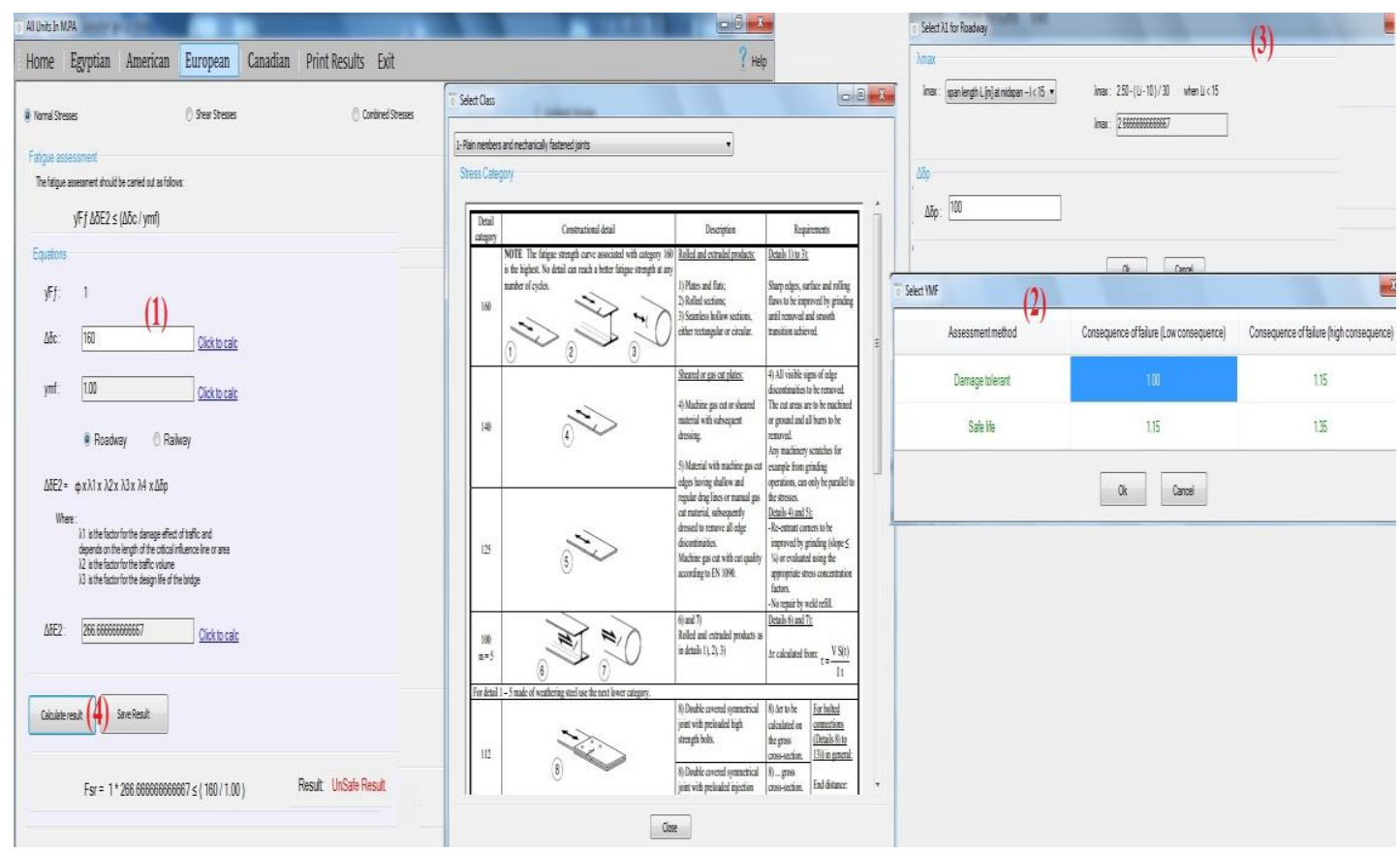

Fig (11): A branch of the performed program representing the Proposal LRFD Egyptian code of practice. 


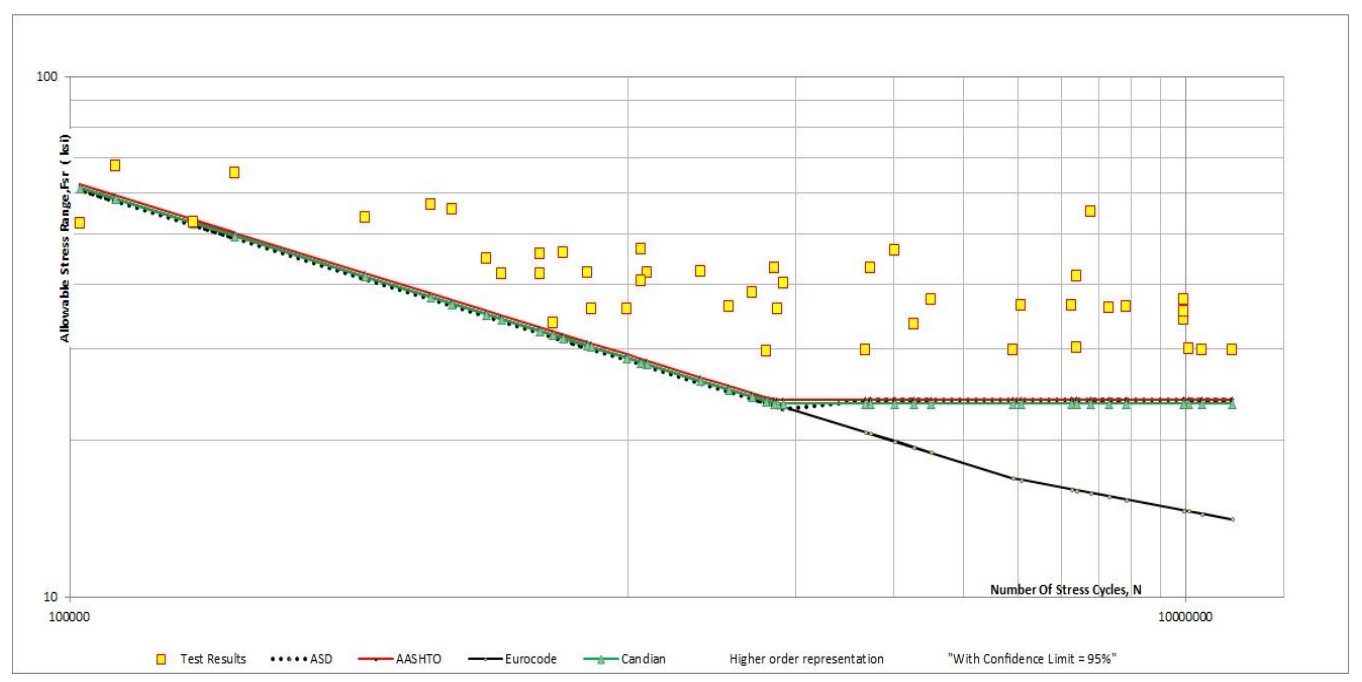

Fig (12): S-N scattered results for 45 specimens representing the rolled beam $(55.56 \%$ of the test

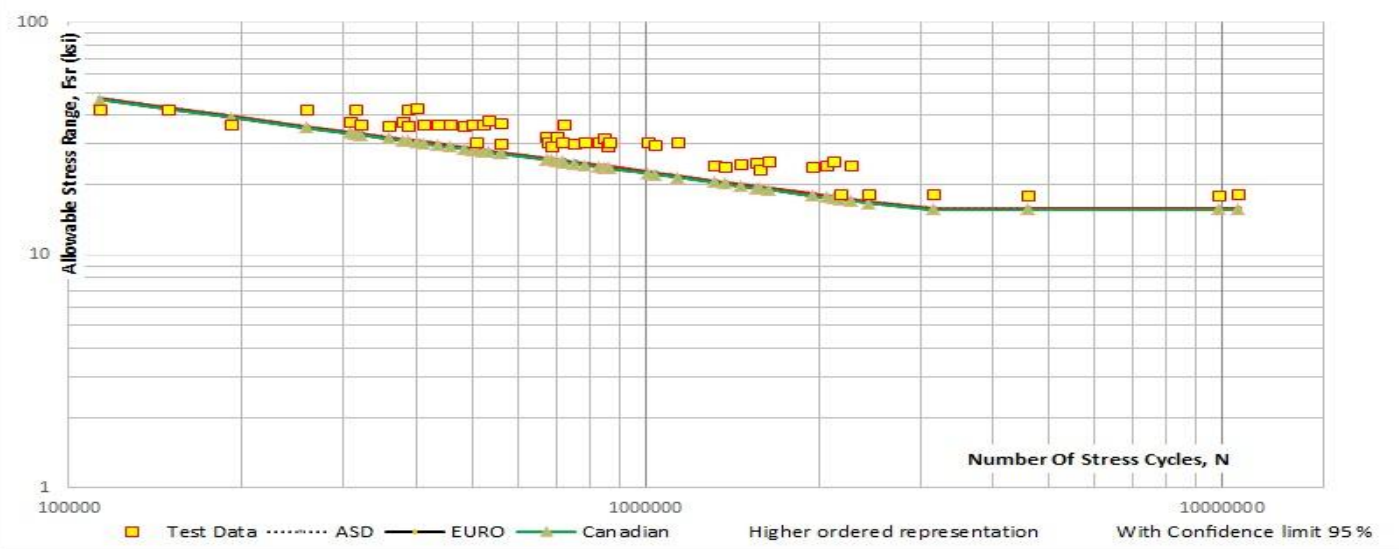

Fig (13): S-N scattered results for 53 specimens representing the built-up sections $(86.8 \%$ of the test results are nearer to the North America).

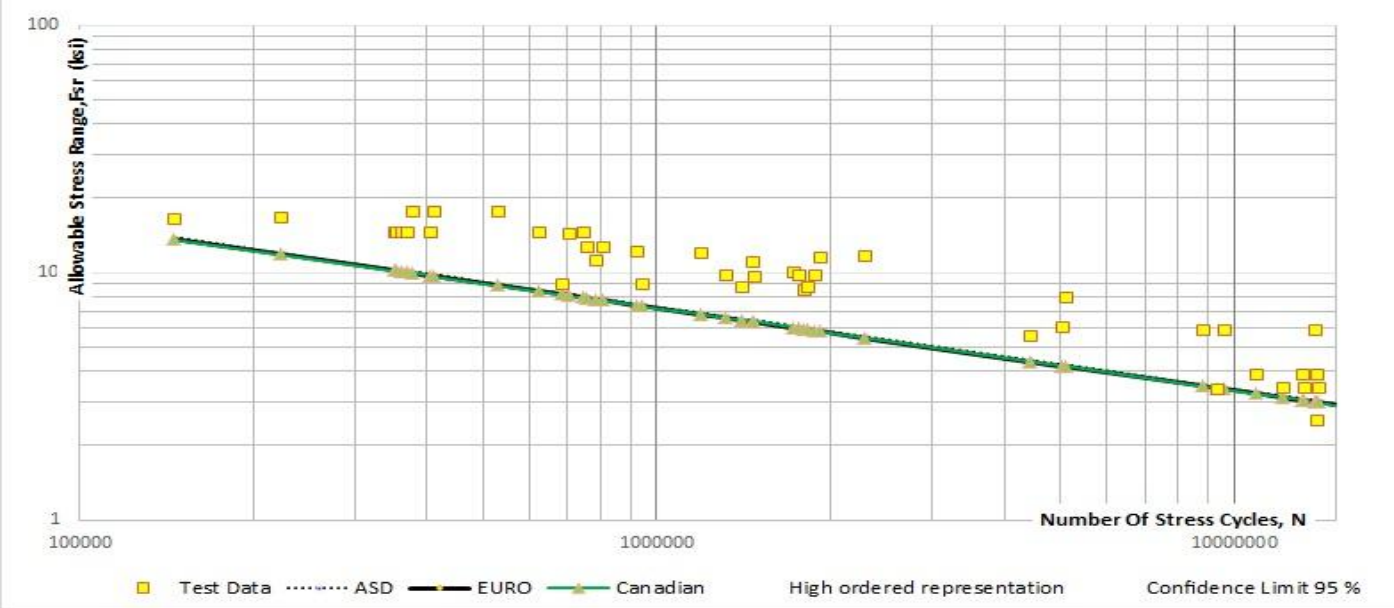

Fig (14): S-N scattered results for 40 specimens representing sections with cover plates $(\mathbf{1 0 0 \%}$ of the test results are nearer to the North America). 


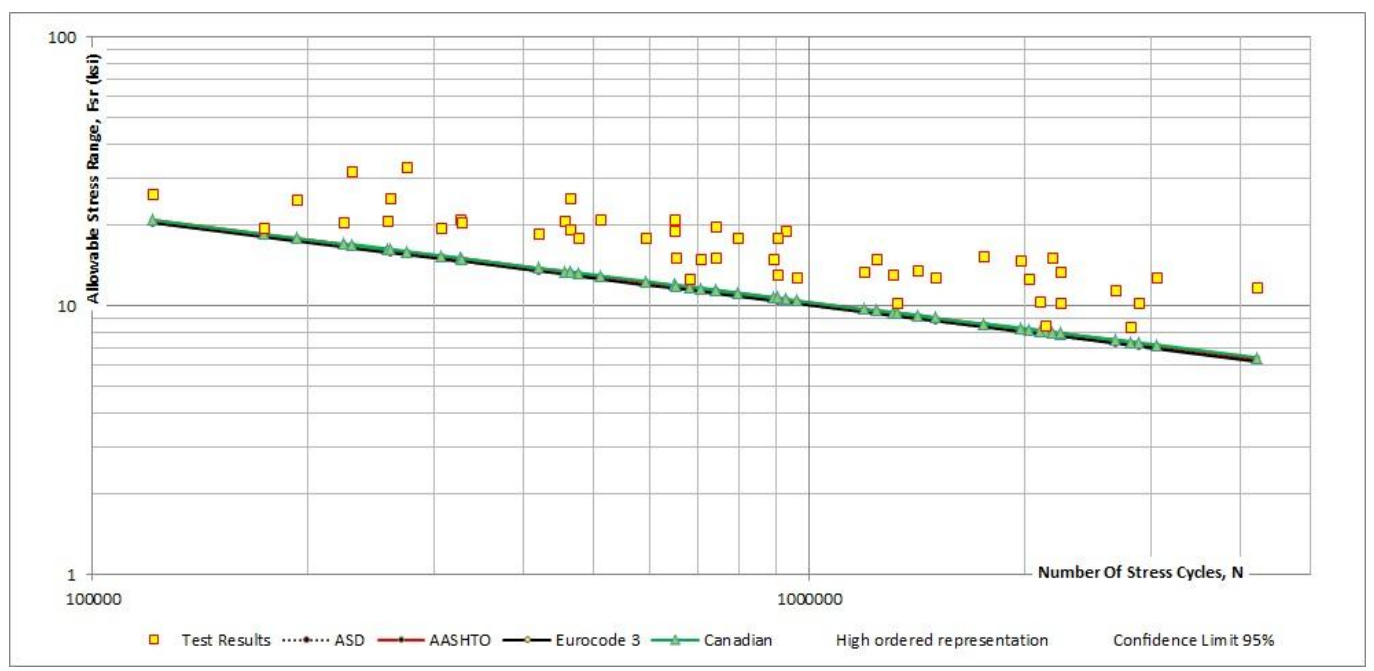

Fig (15): Fig (14): S-N scattered results for 66 specimens representing beams with web attachments $(\mathbf{7 1 . 2 \%}$ of the test results are nearer to the North America).

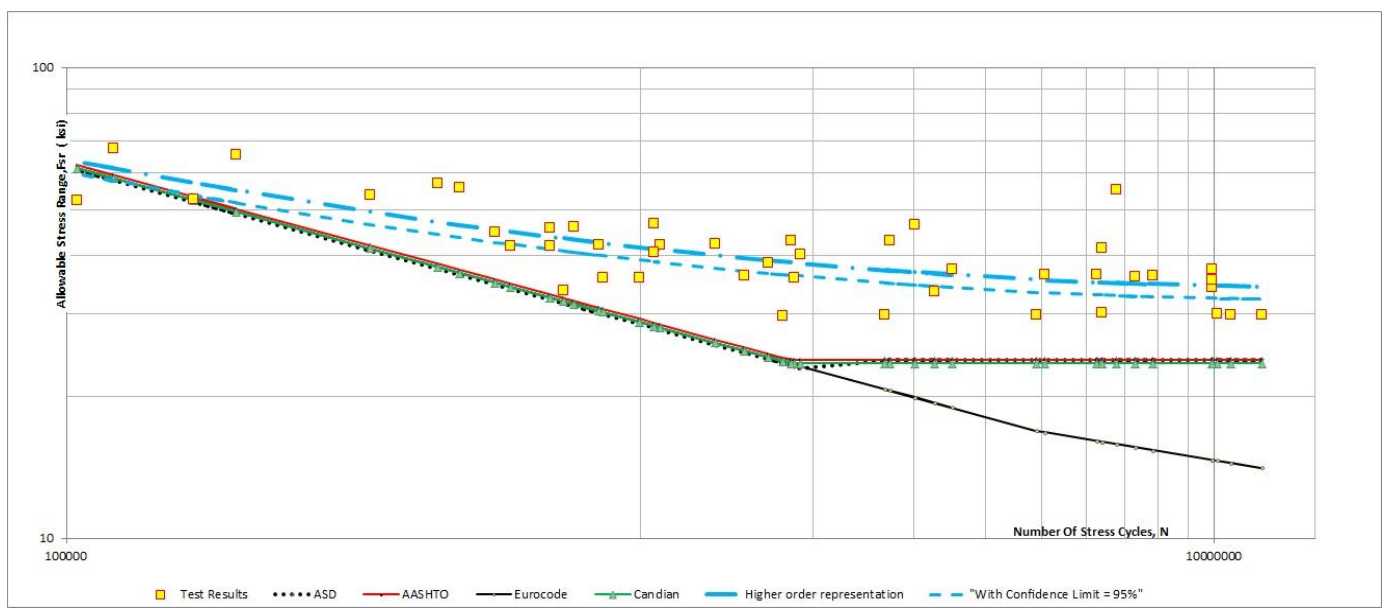

Fig (16): Representing the scattered data of rolled beam specimens by a cubic degree equation satisfying the lower bound of the confidence interval of $95 \%$.

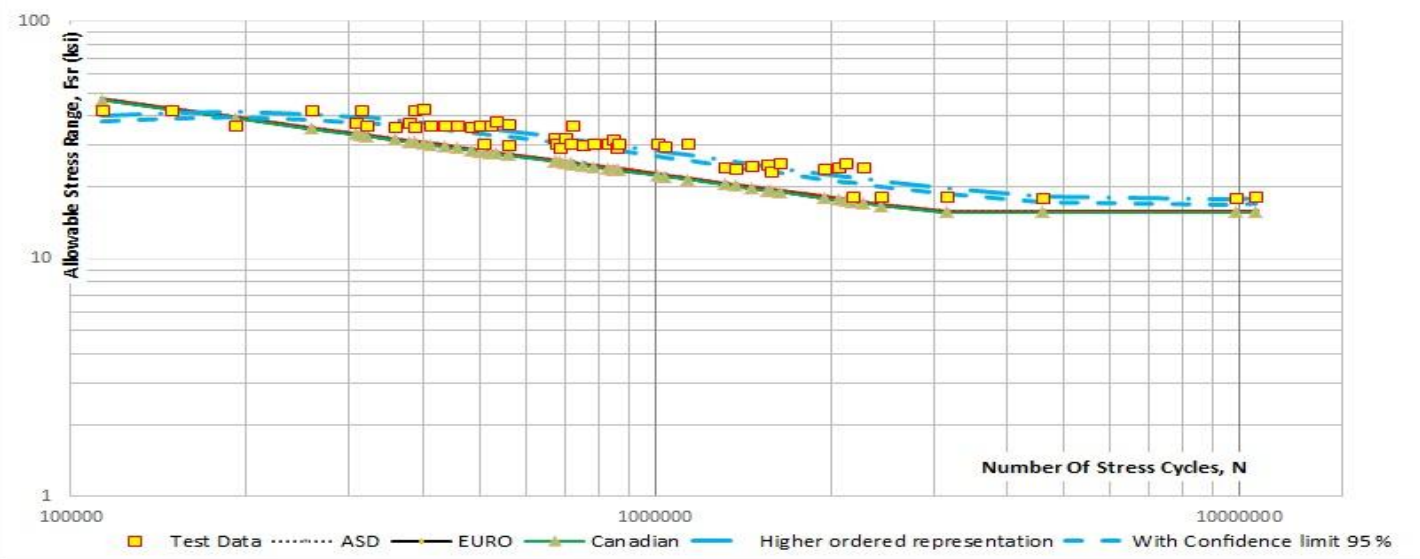

Fig (17): Representing the scattered data of welded beam specimens by a cubic degree equation satisfying the lower bound of the confidence interval of $95 \%$. 


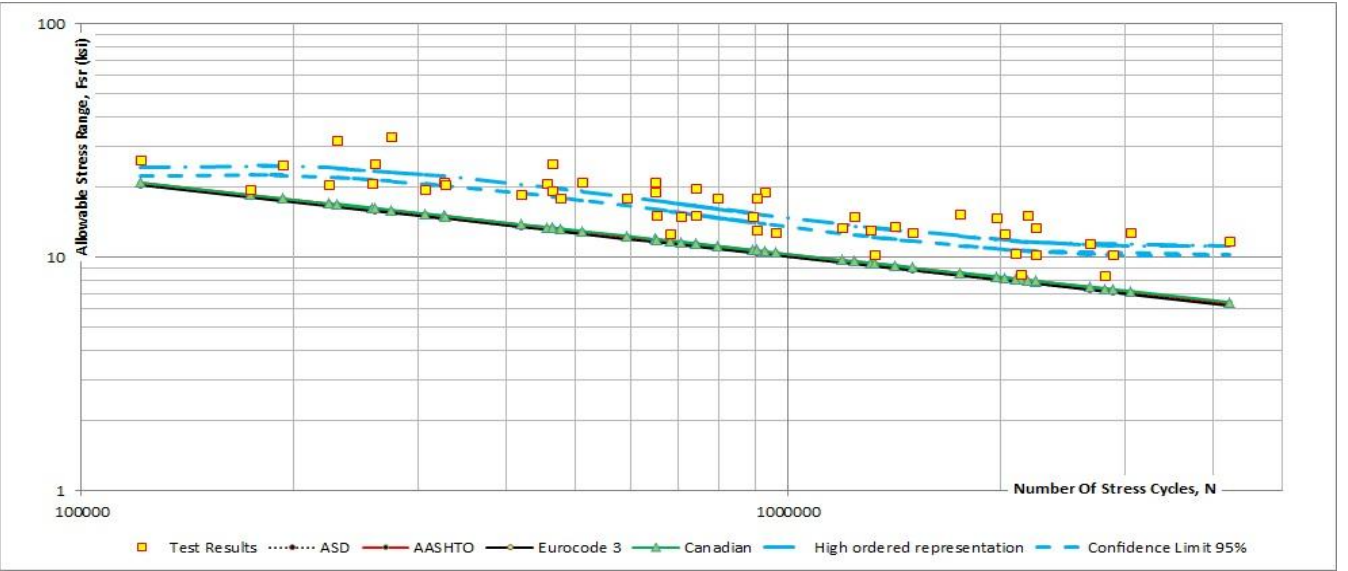

Fig (18): Representing the scattered data of cover-plated sections (Category E) by a cubic degree equation satisfying the lower bound of the confidence interval of $95 \%$.

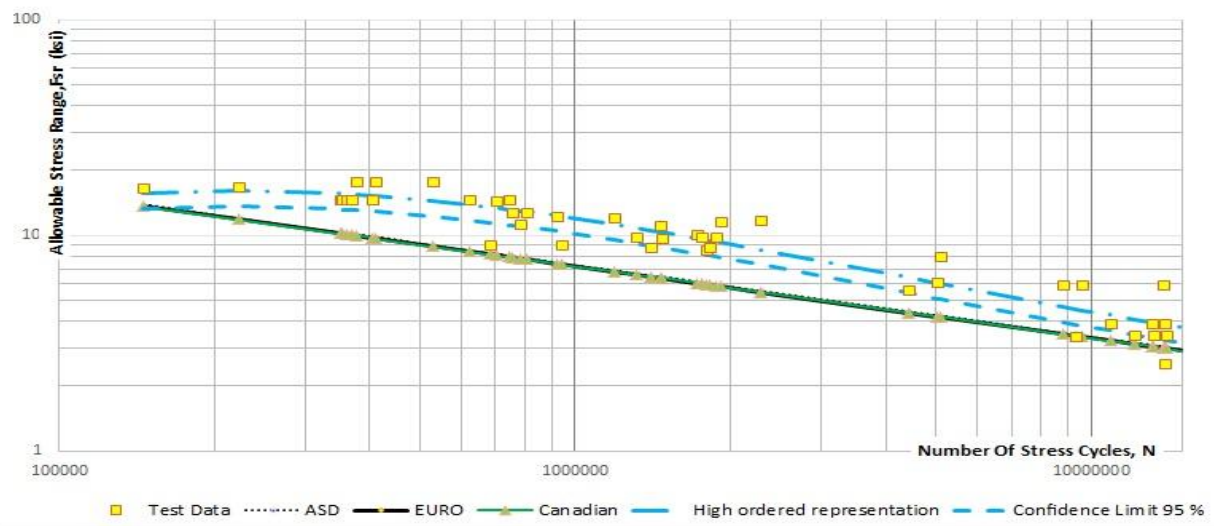

Fig (19): Representing the scattered data of beam with web attachments (Category E') by a cubic degree equation satisfying the lower bound of the confidence interval of $95 \%$.

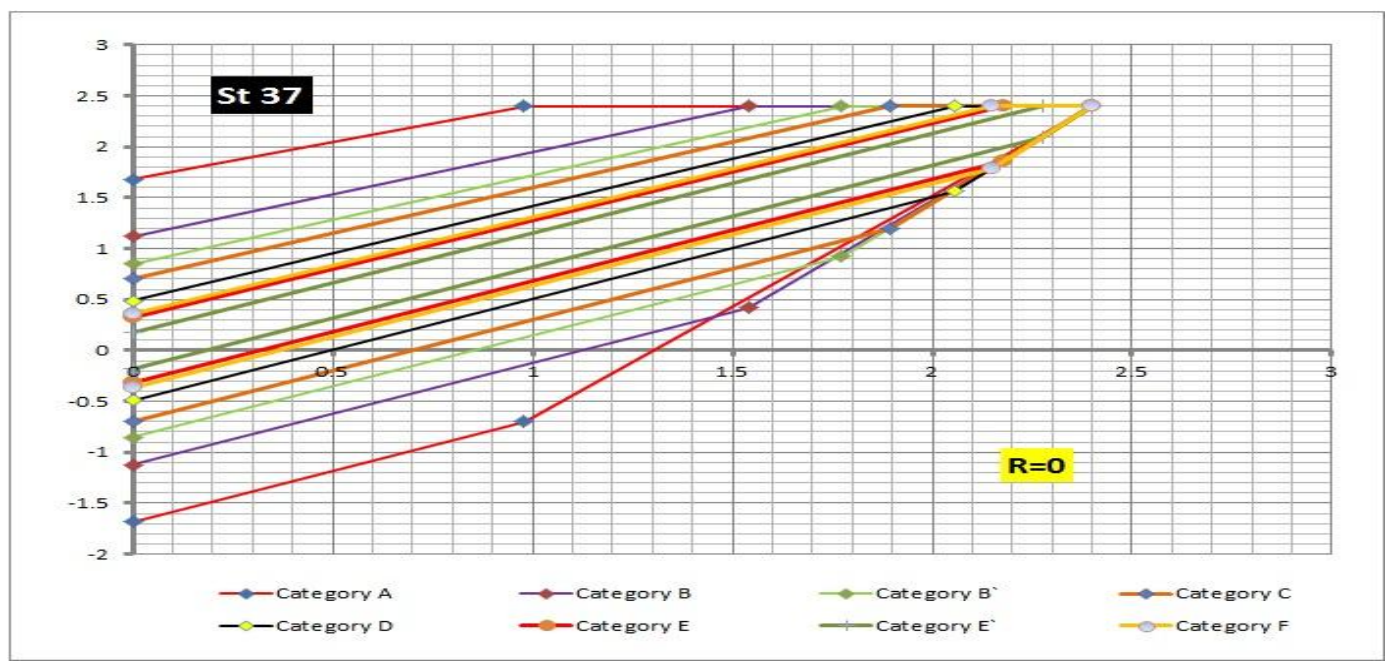

Fig (20): The Safety boundary for (St37) detail categories listed in Egyptian (ASD) according to Smith assumptions 


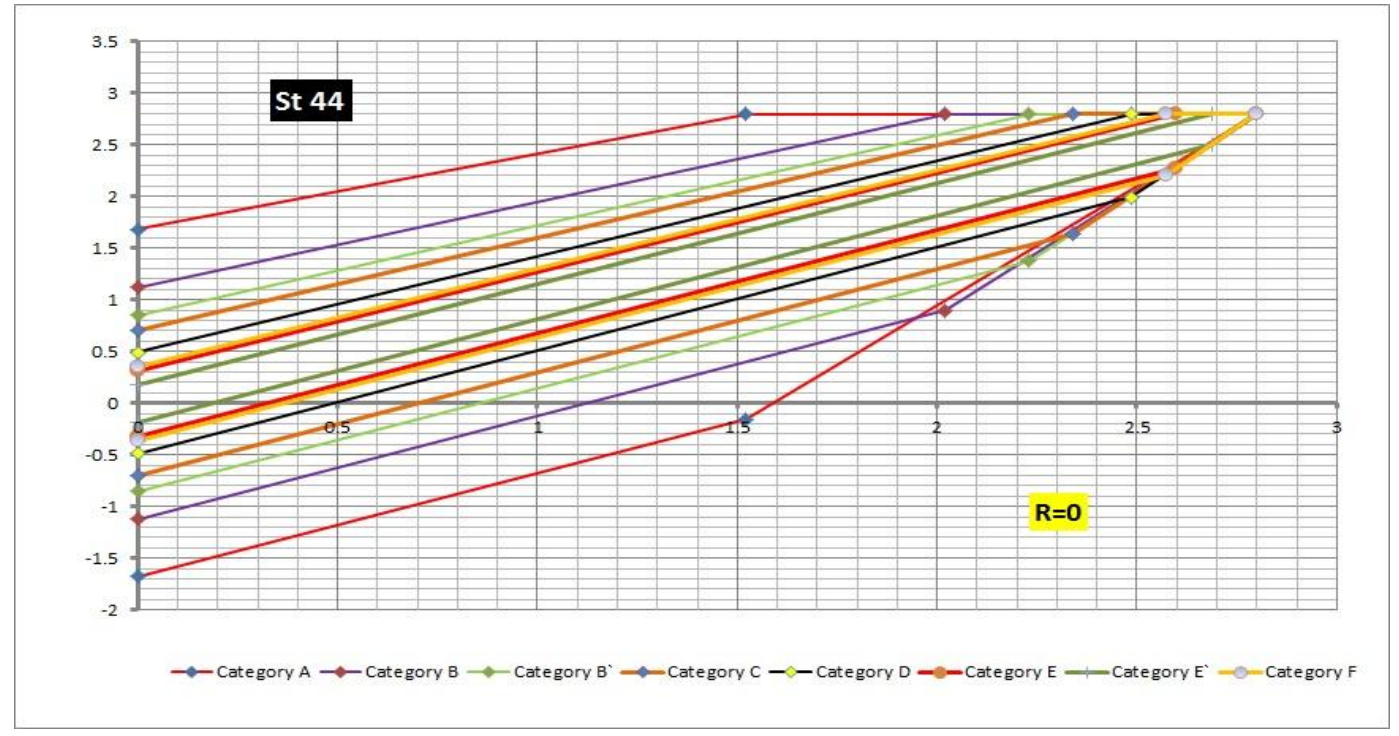

Fig (21): The Safety boundary for (St44) detail categories listed in Egyptian (ASD) according to

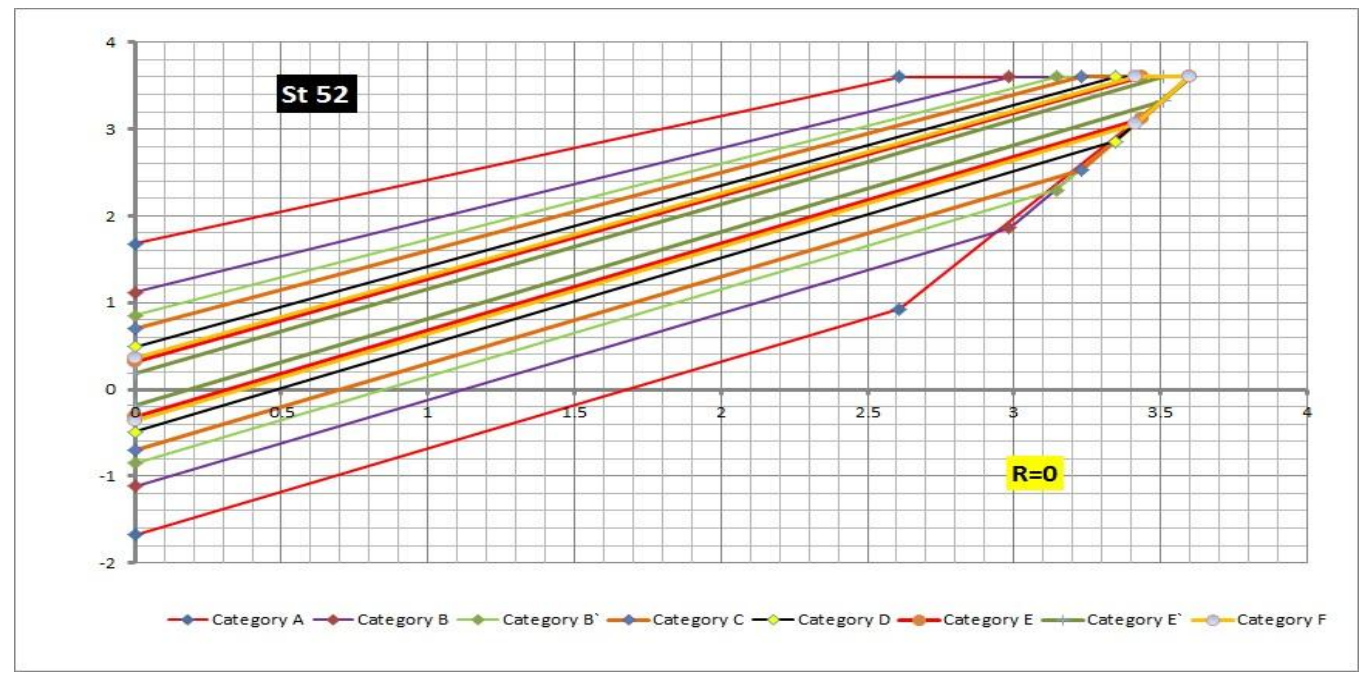

Fig (22): The Safety boundary for (St44) detail categories listed in Egyptian (ASD) according to Smith assumptions 